\title{
Rekayasa Peralatan Ultrafiltrasi untuk PenyediaAn Air Siap Minum bagi Komunitas Pesantren Izzatuna dan Al-Amalul KhaIr di Sumatera Selatan
}

\author{
${ }^{1}$ Subriyer Nasir, ${ }^{2}$ Farida Ali, ${ }^{3}$ Roosdiana Muin \\ ${ }^{1}$ Jurusan Teknik Kimia Universitas Sriwijaya, Jl. Palembang-Prabumulih, Indralaya 30662 \\ e-mail: ${ }^{1}$ subriver@unsri.ac.id, ${ }^{2}$ farida ali@yahoo.com, ${ }^{3}$ dian56@yahoo.com
}

\begin{abstract}
Abstrak. Kegiatan ini dilaksanakan sebagai usaha membantu pondok pesantren dalam hal penyediaan air siap minum yang merupakan prioritas untuk keberlangsungan kegiatan pembinaan santri pada dua pondok pesantren yang ada di perkotaan dan di kabupaten di Propinsi Sumatera Selatan. Metode Ultrafiltrasi menggunakan membran yang dikombinasikan dengan adsorben dan lampu Ultraviolet yang didisain dapat digunakan untuk menghasilkan air yang siap minum sebanyak 800 L per hari. Selain itu peralatan dapat dimanfaatkan oleh pesantren untuk membuka usaha depot air minum.
\end{abstract}

Kata kunci: air minum, pesantren, rekayasa, dan ultrafiltrasi

\section{Pendahuluan}

Penerapan Ipteks bagi Masyarakat (IbM) yang dilaksanakan di Pondok Pesantren Ma'had Izzatunna di Tanjung Api-Api Kecamatan Talang Kelapa, Kabupaten Banyu Asin dan Pesantren Al-Amalul Khair yang berlokasi di kota Palembang dilatarbelakangi oleh fakta bahwa kebutuhan air bersih dan air siap minum menjadi prioritas penting karena jumlah santri yang cukup banyak dan suplai air bersih yang terbatas. Berbagai usaha telah dilakukan oleh pimpinan pondok pesantren misalnya menyediakan sumur bor, melakukan pengolahan air secara sederhana yaitu menggunakan pengendapan dengan tawas. Namun hal ini dirasakan tidak mencukupi karena kualitas air yang dihasilkan masih bermasalah. Di samping suplai yang tidak mencukupi, air yang dihasilkan berwarna kuning kecoklatan dan berbau (Ali, dkk, 2012 Nasir, dkk 2013).

Pondok pesantren Ma'had Izzatuna berdiri sejak tahun 2005 dan mengelola TK, SD, SMP dan Madrasah Aliyah serta memiliki santriwan/wati sebanyak 300 orang yang diasuh oleh 41 orang guru. Lembaga Pendidikan TK, SD dan SMP Islam Terpadu Izzatuna mengintegrasikan kurikulum Diknas, Depag dan Pesantren dengan visi menghasilkan generasi islami dan berakhlakul karimah, mengedepankan sejumlah program unggulan seperti program parenting atau kerjasama antar wali siswa melalui kegiatan-kegiatan bernuansa islami seperti pengajian bersama. Selain itu terdapat juga pendidikan biligual bahasa Arab dan Inggris, pembangunan karakter, tahfiz al-quran, dan tabligh selain pengenalan dunia entreprenuer diantaranya pembibitan ikan, beternak ayam hingga pertanian dan perkebunan, sains dan teknologi serta olahraga dan musik.

Untuk kegiatan sehari-hari seperti kebutuhan mandi dan mencuci santri mengandalkan air rawa yang terdapat pada beberapa kolam yang ada di sekitar kompleks pesantren. Berbagai usaha telah dilakukan untuk mengolah air rawa tersebut menjadi air bersih. Namun demikian kualitas air yang diperoleh masih dirasakan tidak memadai karena berwarna kuning kecoklatan dan berbau. Untuk keperluan minum dan memasak mereka mengandalkan air minum isi ulang. Hal ini juga dialami oleh beberapa desa yang pernah dijadikan lokasi pengabdian kepada masyarakat oleh tim Fakultas 
Teknik Unsri (Nasir, dkk 2010). Untuk itu tim juga pernah melaksanakan kegiatan pengabdian kepada masyarakat pada beberapa sekolah dan penduduk di kabupaten Ogan Ilir (Nasir, dkk 2011) dan kabupaten Ogan Komering Ilir (Nasir, dkk 2014) serta Saleh, dkk (2015).

Pondok Pesantren Al-Amalul Khair berlokasi di Kelurahan Lorok Pakjo, Kecamatan Ilir Barat I, Kota Palembang di atas areal seluas 30 ha, dan memiliki bangunan seluas $2000 \mathrm{~m}^{2}$. Yayasan Pondok Pesantren Al-Amalul Khair melaksanakan pendidikan menghafal serta mengkaji Ulum Al-Quran dan kitab kuning juga melaksanakan pendidikan formal mulai dari tingkat madrasah ibtidaiyah (SD), Tsnawiyah (SMP) dan SMA Islam Al-Amalul Khair yang semua terakreditasi Baik (B). Saat ini Pondok Pesantren Al-Amalul Khair memiliki tenaga pendidik berjumlah 38 orang guru yang mengasuh 670 orang santri.

Untuk keperluan air bersih sehari-hari Pondok Pesantren Al Amalul Khair menggunakan 2 buah sumur bor (untuk keperluan cuci dan mandi) serta air PDAM untuk minum. Ada dua sumur bor yang berada di kawasan Pondok pesantren ini yang diharapkan dapat memenuhi kekurangan pasokan air dari PDAM. Mengingat kebutuhan air yang cukup besar setiap hari di pondok pesantren ini sebagaian besar dipenuhi oleh sumur bor karena dianggap dapat memenuhi kebutuhan air untuk sehari hari misalnya untuk cuci, mandi dan wudhu. Air bersih dari PDAM dikhususkan untuk memenuhi kebutuhan air minum. Permasalahan yang dihadapi oleh pesantren ini adalah air yang disuplai oleh dua buah sumur bor keruh dan berbau. Hal ini tentu saja mengurangi kenyamanan dan kesehatan di komunitas pondok pesantren.

Diperlukan usaha-usaha untuk membantu santri yang berada di pondok pesantren ini agar dapat memanfaatkan air sumur bor untuk kebutuhan selain air minum. Untuk itu, tim pengusul dan mitra menganggap persoalan pengadaan air bersih merupakan skala prioritas di samping pengembangan fisik lainnya. Khusus untuk pesantren Al-Amalul Khair juga pernah mendapatkan penyuluhan dan bantuan peralatan penjernih air dari tim pengusul (Ali, dkk 2012). Namun demikian karena kapasitas peralatan yang masih belum memenuhi kebutuhan warga pesantren maka masih diperlukan langkah selanjutnya yaitu dengan menawarkan metode pengolahan air baku dengan teknologi filtrasi berbasis membran.

Program kegiatan ini didanai oleh DP2M Dikti Kemenristek Dikti melalui program Iptek bagi Masyarakat (IbM) tahun 2014 dan bertujuan untuk membantu pondok pesantren dalam perancangan dan instalasi peralatan Ultrafiltrasi untuk 1) mengatasi kebutuhan air bersih untuk komunitas pesantren, 2) memberikan penyuluhan mengenai air yang layak dikonsumsi kepada santri pondok pesantren, dan 3) memberikan pengetahuan kepada santri mengenai teknik pengolahan air sumur atau air permukaan menjadi air bersih dan air siap minum serta 4) membantu pondok pesantren dalam hal pengadaan air bersih untuk keperluan sehari hari. Kegiatan ini bermanfaat dalam hal menciptakan hubungan/interaksi positif antara masyarakat kampus dengan pondok pesantren dan masyarakat sekitar serta membantu komunitas pesantren dalam merancang unit pengolahan air sumur atau air permukaan menjadi air bersih guna keperluan sehari hari. Selain itu juga akan membantu santri untuk membuka usaha dalam pengolahan air minum setelah mereka menyelesaikan pendidikannya.

Penggunaan teknologi membran dalam hal ini ultrafiltrasi merupakan suatu cara yang cukup cepat dalam menghasilkan air bersih bahkan air siap minum. Namun demikian diperlukan perawatan berkala agar peralatan dapat berfungsi optimal. Kualitas umpan tentu saja sangat berpengaruh pada kinerja membran. Umpan (feed) yang tidak 
sesuai dengan persyaratan membran akan mempercepat terjadinya fouling pada membran. Untuk itu perlu dikombinasikan dengan penggunaan adsorben untuk mengurangi kadar TDS, TSS, ion logam seperti besi dan mangan (Nobble \& Stern, 2003; Nasir, dkk 2015a).

Tahap pertama ujicoba dan peragaan cara kerja peralatan yang didisain terlebih dahulu pada kegiatan Kuliah Kerja Nyata Tematik Mahasiswa Jurusan Teknik Kimia Fakultas Teknik Universitas Sriwijaya pada tanggal 6 Juni 2015 di desa Rambutan Kecamatan Rambutan Kabupaten Banyuasin yang berjarak sekitar $45 \mathrm{~km}$ dari kota Palembang (Nasir, dkk, 2015b; Saleh, dkk 2015). Mahasiswa yang dilibatkan berjumlah 10 orang. Pada kegiatan ini telah dilakukan demonstrasi peralatan yang didisain (Gambar 1) dengan cara mengolah langsung air sumur penduduk yang mempunyai $\mathrm{pH}$ $=5$. Hasilnya peralatan mampu mengubah air sumur dengan keasaman rendah menjadi air yang dapat diminum.

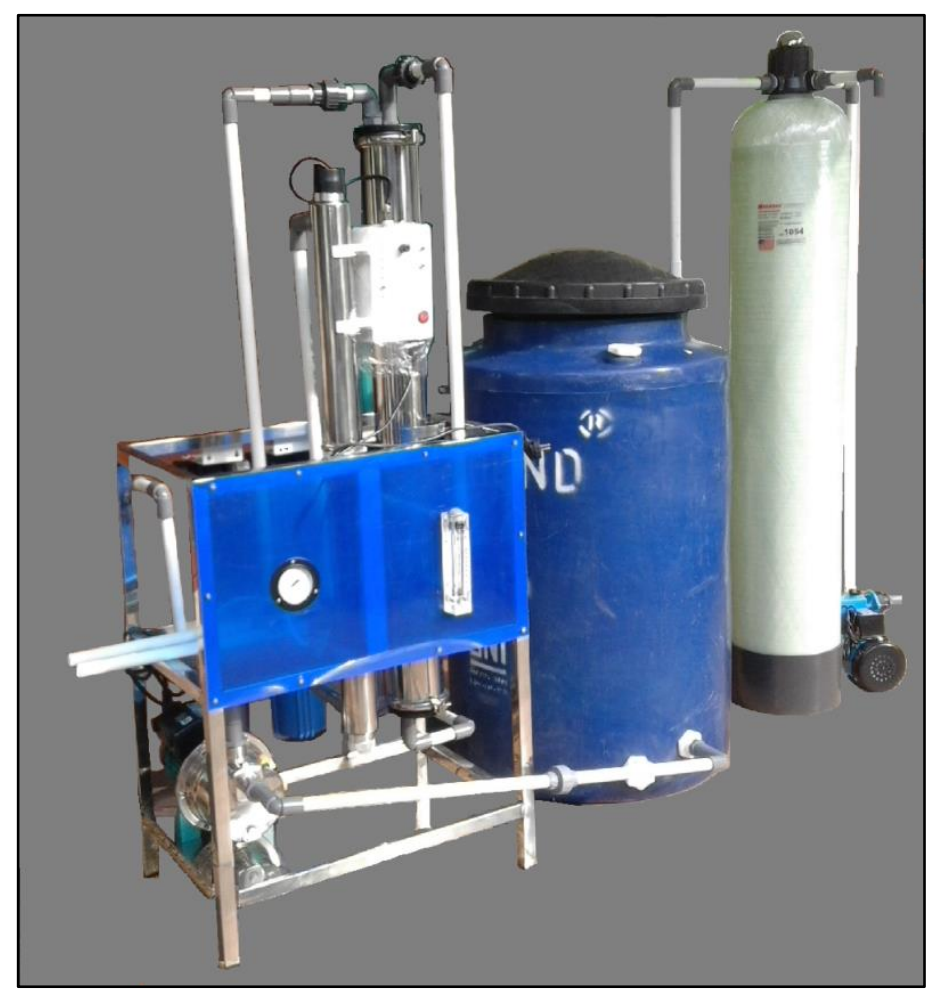

Gambar 1. Rangkaian Peralatan Ultrafiltrasi

Peralatan yang dirancang dalam kegiatan ini terdiri dari modul Ultrafiltrasi yang dilengkapi dengan membran type HM90UF, tanki Tedmon kapasitas 220 L, Pompa Stainless Steel, Pompa centrifugal, Cartridge Filter Polyethylene, Perangkat Sterilisasi Ultraviolet, Tabung adsorben type FRP, Flowmeter 5 GPM, dan sebuah Pressure Gauge. Rangka (dudukan) peralatan dibuat dari stainless steel. Untuk membantu operator, peralatan juga dilengkapi dengan Petunjuk Pengoperasian Alat.

\section{Pelaksanaan Kegiatan}

Kegiatan diadakan bertepatan dengan pelepasan/ wisuda siswa Madrasah Ibtidaiyah, Madrasah Tsnawaiyah dan SMA Al Amalul Khair. Kegiatan diikuti oleh siswa, guru dan wali murid dan dihadiri oleh pimpinan pesantren Al Amalul Khair. 
Kesempatan memberikan sambutan dalam acara pelepasan itu dimanfaatkan untuk menjelaskan kedatangan tim IbM ke Pesantren Al Amalul Khair. Tanggapan positip dari pimpinan pesantren, siswa dan guru terhadap kegiatan ini. Untuk pondok pesantren Ma'had Izzatuna kegiatan dilaksanakan dan dihadiri langsung oleh pimpinan pondok pesantren, guru dan santri. Kegiatan dilakukan dengan cara demonstrasi penggunaan alat dan diskusi di lapangan serta evaluasi dengan cara menyebarkan kuisioner berisi 10 buah pertanyaan terhadap para peserta. Akhir kegiatan ditandai dengan penyerahan peralatan kepada pimpinan kedua pondok pesantren. IbM.

Berikut daftar pertanyaan dan respon responden dari ke dua lokasi pengabdian

1. Apakah anda mengerti dengan penjelasan yang diberikan?
A. Sangat mengerti
C. Kurang mengerti
B. Cukup mengerti
D. Tidak mengerti

Dari jawaban yang diberikan 20,6\% peserta menjawab sangat mengerti, 70,6\% cukup mengerti terhadap materi yang disampaikan.

2. Apakah materi yang disampaikan :
A. Sangat bermanfaat
C. Kurang bermanfaat
B. Cukup bermanfaat
D. Tidak bermanfaat

Terhadap pertanyaan ini respon peserta menyatakan sangat bermanfaat (70\%), dan cukup bermanfaat (24\%). Hal ini menunjukkan bahwa kegiatan ini memberikan manfaat cukup besar bagi peserta.

3. Apakah cara penyampaian materi:
A. Sangat mudah dipahami
C. Kurang dipahami
B. Cukup mudah dipahami
D. Tidak dipahami

Terhadap pertanyaan ini $43 \%$ responden menyatakan sangat paham dan sekitar $40 \%$ menyatakan cukup paham.

4. Menurut anda kedatangan tim PPM FT.Unsri
A. Sangat bermanfaat
C. Kurang bermanfaat
B. Cukup bermanfaat
D. Tidak bermanfaat karena......

Terhadap pertanyaan ini $54 \%$ responden menganggap kedatangan tim pengabdian FT.Unsri ke tempat mereka sangat memberikan manfaat.

5. Menurut anda kebutuhan air di pesantren ini:
A. Cukup lancar dan kualitas baik
C. Tidak mencukupi, kualitas baik
B. Tidak lancar dan kualitas kurang baik
D. Kualitas sudah baik

Dari kesan yang diperoleh oleh responden, sekitar 59\% menyatakan lancar dan baik dan sekitar $8 \%$ menyatakan tidak lancar tapi kualitas baik. Dan $16 \%$ yang menyatakan jelek dan tidak ada yang mengatakan kualitasnya sudah baik.

6. Untuk kebutuhan air minum di rumah apakah anda menggunakan :
A. Air sungai
C. Air PAM
B. Air rawa
D. Air Sumur

Sebagian besar responden (44\%) memanfaatkan air PAM dan $41 \%$ air sumur untuk memenuhi kebutuhan air minum sehari hari mereka.

7. Menurut anda topik yang disampaikan oleh tim ;
A. Sangat sesuai dengan kebutuhan anda
C. Kurang dibutuhkan
B. Cukup sesuai dengan situasi ditempat anda
D. Tidak diperlukan

Terhadap pertanyaan ini 53\% responden menyatakan bahwa kegiatan ini sangat sesuai dengan kebutuhkan mereka. Sekitar $29 \%$ menyatakan cukup sesuai dengan yang dibutuhkan mereka. 
8. Kalau ada penyuluhan sejenis lainnya yang akan disampaikan oleh tim FT.unsri apakah anda :
A. Bersedia mengikutinya
C. Tidak bersedia
B. Sangat senang sekali dan bersedia ikut serta
D. Kurang bersedia

Pada umumnya (90\%) responden menyatakan sangat senang dengan adanya kegiatan ini dan bersedia ikut serta dalam kegiatan berikutnya.

9. Selain materi diatas menurut anda hal apa yang dirasakan perlu juga untuk disampaikan oleh tim FT.Unsri :
A. Teknologi tepat guna
C. Teknologi komputer/ elektronika/ listrik
B. Teknologi Pertanian
D. Lainnya yaitu

Feedback dari responden memperlihatkan bahwa kegiatan pengabdian yang juga dibutuhkan pada kegiatan selanjutnya yaitu teknologi pertanian $(11 \%)$ dan teknologi tepat guna $(44 \%)$.

10. Menurut anda kegiatan pengabdian dari tim FT.Unsri ke tempat anda sebaiknya:
A. Enam bulan sekali
C. Tiga bulan sekali
B. Setiap bulan
D. Setahun sekali

Umumnya responden menyatakan bahwa kegiatan seperti ini paling tidak diadakan setiap tiga bulan (14\%) dan enam bulan (27\%) sekali. Dan 14\% santri menginginkan agar kegiatan serupa diadakan setiap bulan.

Hasil respon peserta ditampilkan pada Gambar gambar berikut ini.

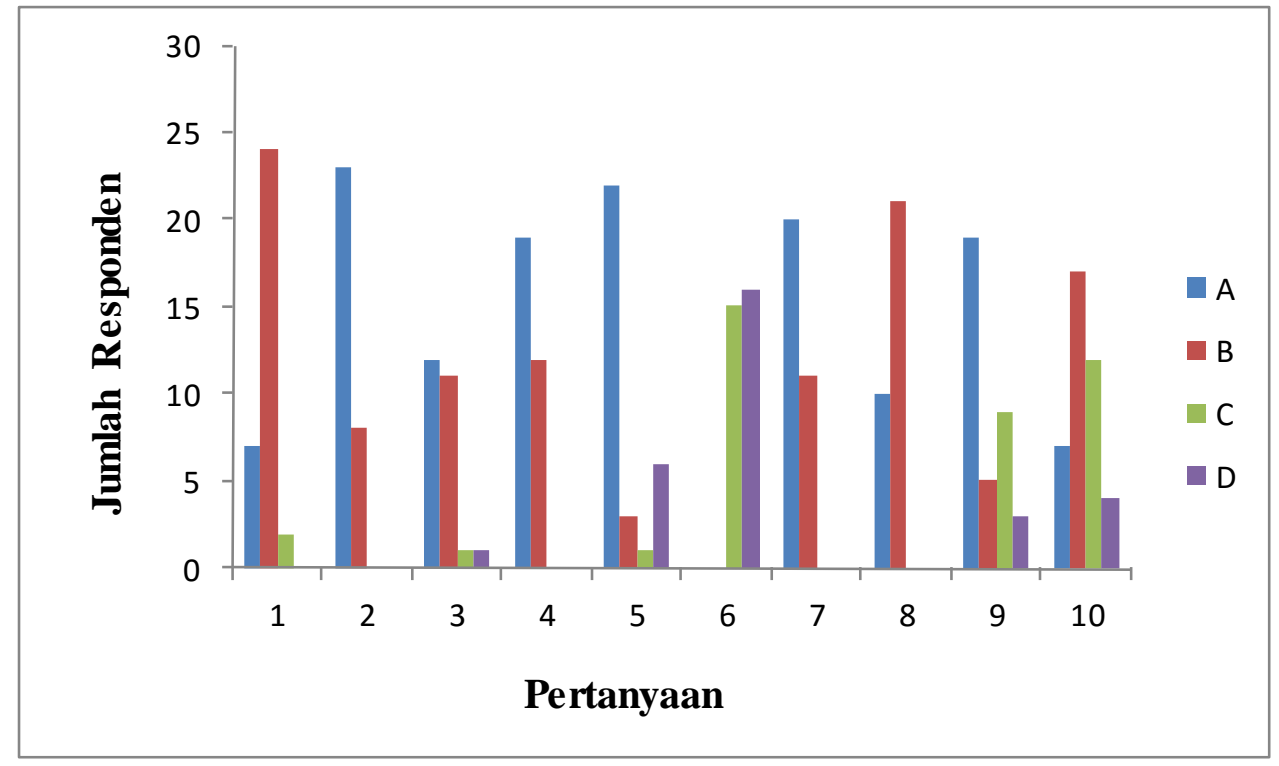

Gambar 2. Pilihan responden terhadap jenis pertanyaan

\section{Kesimpulan dan Saran}

Air bersih merupakan prioritas di kebanyakan daerah di Propinsi Sumatera Selatan yang belum terjangkau oleh PDAM. Topografi Propinsi Sumatera Selatan yang tergolong dataran rendah yang sebagian besar merupakan rawa-rawa dan sungai memerlukan peralatan/treatment yang sesuai agar sumber air menjadi layak untuk diolah menjadi air bersih dan air minum. Peralatan ultrafiltrasi yang diserahkan oleh tim dapat dimanfaatkan untuk memenuhi kebutuhan air minum santri dan juga mempunyai 
prospek ekonomi untuk dikembangkan menjadi depot air minum komersial. Kegiatan IbM ke depan sebaiknya juga diarahkan ke daerah pesisir Sumatera Selatan yang sumber airnya merupakan air payau yang tidak dapat dimanfaatkan oleh penduduk tanpa pengolahan lebih lanjut.

\section{Daftar Pustaka}

Ali, Farida. dkk (2012), Teknologi Filtrasi Air Sumur Menjadi Air Bersih Untuk Santri Pondok Pesantren Al Amalul Khair Palembang, Laporan PPM DIPA FT.Unsri, Indralaya

Nasir, Subriyer, dkk (2013), Penyuluhan Pengolahan Air Sungai dengan Metoda Ultrafiltrasi untuk Penduduk Desa Sukaraja Sp.Padang Ogan Komering Ilir, Laporan PPM Dana FT Unsri, Indralaya

Nasir, Subriyer, Budiman, dan Mulkan Jailani (2013), Pengaruh Tekanan Operasi pada Sistem Pengolahan Air Rawa Menjadi Air Bersih Menggunakan Saringan Pasir Lambat dan Filter Keramik, Prosiding Seminar AVOER 5, Palembang.

Nasir, Subriyer,. dkk (2012), Peningkatan Kualitas Air Sungai/Rawa Menjadi Air Bersih dengan Teknologi Filtrasi untuk Penduduk di Kecamatan Jejawi Kabupaten Ogan Komering Ilir, Laporan PPM DIPA FT.Unsri

Nasir, Subriyer, dkk (2011), Perangkat Sederhana Pengolahan Air Rawa Menjadi Air Bersih di Kecamatan Pemulutan Ogan Ilir, DIPA FT.Unsri

Nasir, Subriyer, Eddy Ibrahim, and A. Taufik Arief (2014), Perancangan Plant Pengolahan Air Asam Tambang Dengan Proses Sand Filtrasi, Ultrafiltrasi Dan Reverse Osmosis, Prosiding SNaPP: Sains, Teknologi, dan Kesehatan, Unisba, Bandung

Nasir, Subriyer., M. Said, A. R. Fachry (2014), Pengolahan Air Sungai menjadi Air Bersih dengan Metoda Ultrafiltrasi untuk Penduduk Desa Sukaraja Kabupaten Ogan Komering Ilir Sumatera Selatan, Prosiding SNAPP 2014, Unisba, Bandung.

Nasir, Subriyer, Farida Ali, Rosdiana Mu'in (2015), Aplikasi Teknologi Ultrafiltrasi untuk Penyediaan Air Bersih bagi Komunitas Pondok Pesantren Ma'had Izzatuna Kabupaten Banyuasin dan Pondok Pesantren Al-Amalul Khair di Kota Palembang Propinsi Sumatera Selatan, Laporan Akhir Ipteks bagi Masyarakat DP2M, Universitas Sriwijaya, Indralaya

Nobble, R.D dan S.A. Stern (2003), Membrane Separations Technology: Principles and Applications, Else viere, Amsterdam

Saleh, Abdullah, Subriyer Nasir, Farida Ali, Rosdiana Mu'in, Prahady Susmanto (2015), Teknologi Ultrafiltrasi untuk Pengolahan Air Sumur bagi Penduduk Desa Rambutan, Kecamatan Rambutan, Kabupaten Banyuasin, Laporan Pengabdian Masyarakat, Lembaga Pengabdian Masyarakat Universitas Sriwijaya. 